\title{
Article \\ Chemical Bond Formation between Vertically Aligned Carbon Nanotubes and Metal Substrates at Low Temperatures
}

\author{
Chaminda P. Nawarathne, Abdul Hoque $\mathbb{D}^{D}$, Chethani K. Ruhunage, Connor E. Rahm and Noe T. Alvarez *(D) \\ Department of Chemistry, University of Cincinnati, Cincinnati, OH 45221, USA; nawarawp@mail.uc.edu (C.P.N.); \\ hoqueml@mail.uc.edu (A.H.); ruhunack@mail.uc.edu (C.K.R.); rahmcr@mail.uc.edu (C.E.R.) \\ * Correspondence: alvarene@ucmail.uc.edu; Tel.: +1-513-556-9370
}

check for updates

Citation: Nawarathne, C.P.; Hoque, A.; Ruhunage, C.K.; Rahm, C.E.; Alvarez, N.T. Chemical Bond Formation between Vertically Aligned Carbon Nanotubes and Metal Substrates at Low Temperatures. Appl. Sci. 2021, 11 , 9529. https://doi.org/10.3390/ app11209529

Academic Editor: Henrique Leonel Gomes

Received: 20 September 2021 Accepted: 6 October 2021

Published: 14 October 2021

Publisher's Note: MDPI stays neutral with regard to jurisdictional claims in published maps and institutional affiliations.

Copyright: (c) 2021 by the authors. Licensee MDPI, Basel, Switzerland. This article is an open access article distributed under the terms and conditions of the Creative Commons Attribution (CC BY) license (https:// creativecommons.org/licenses/by/ $4.0 /)$.

\begin{abstract}
The exceptional physical properties of carbon nanotubes (CNTs) have the potential to transform materials science and various industrial applications. However, to exploit their unique properties in carbon-based electronics, CNTs regularly need to be chemically interfaced with metals. Although CNTs can be directly synthesized on metal substrates, this process typically requires temperatures above $350^{\circ} \mathrm{C}$, which is not compatible for many applications. Additionally, the CNTs employed here were highly densified, making them suitable as interconnecting materials for electronic applications. This paper reports a method for the chemical bonding of vertically aligned CNTs onto metal substrates that avoids the need for high temperatures and can be performed at temperatures as low as $80^{\circ} \mathrm{C}$. Open-ended CNTs were directly bonded onto $\mathrm{Cu}$ and $\mathrm{Pt}$ substrates that had been functionalized using diazonium radical reactive species, thus allowing bond formation with the openended CNTs. Careful control during grafting of the organic species onto the metal substrates resulted in functional group uniformity, as demonstrated by FT-IR analysis. Scanning electron microscopy images confirmed the formation of direct connections between the vertically aligned CNTs and the metal substrates. Furthermore, electrochemical characterization and application as a sensor revealed the nature of the bonding between the CNTs and the metal substrates.
\end{abstract}

Keywords: carbon nanotubes; metal-carbon interface; bond formation

\section{Introduction}

Carbon nanotubes (CNTs) are macromolecules whose discovery, arguably attributable to Professor Sumio Iijima [1,2], has provided heretofore unimagined potential for engineering applications. CNTs have garnered immense research interest because of their unique structure and physical properties [3-5]. At the nanoscale level, they exhibit very high strength and electrical and thermal conductivities [6-8]. Single-walled CNTs have been shown to have a Young's modulus of greater than $1 \mathrm{TPa}$ [9], with an electrical resistivity as low as $3 \times 10^{-7} \Omega \mathrm{m}[10]$ and a thermal conductivity as high as $3000 \mathrm{Wm} \mathrm{K}^{-1}[11,12]$. Furthermore, CNTs have been reported to have a large ampacity compared with metals, suggesting their untapped potential in electronics [13]. In addition, the heat dissipation capabilities of CNT arrays as thermal interfaces have been demonstrated [14]. Several researchers have attempted to prepare $\mathrm{CNT} / \mathrm{Cu}$ composites with varying degrees of success [15-17], but in order to take advantage of CNTs' physical properties, significant efforts have been devoted to growing CNTs on metal substrates in order to achieve chemical bonding [18-20].

Chemical vapor deposition (CVD) has been adopted as the most effective and suitable method for synthesizing vertically aligned CNTs on metals, but traditional CVD requires temperatures above $650{ }^{\circ} \mathrm{C}$ to produce high-quality CNTs. It has been reported that high temperatures negatively affect the lifetime of the catalyst nanoparticles by promoting catalyst ripening, carbide formation, alloying, and coarsening [21,22]. Both the essential necessity of an $\mathrm{Al}_{2} \mathrm{O}_{3}$ support during synthesis and the negative effect of its dielectric nature 
on limiting the electron transport process have been demonstrated [23]. High-density CNT arrays that can support interconnections have been developed [24-26]. However, the creative approaches required to synthesize CNTs directly on metal substrates, including $\mathrm{Cu}, \mathrm{Al}, \mathrm{Ti}, \mathrm{Ta}$, and stainless steel, demonstrate the challenges involved in growing highquality CNTs [18,26-28]. In addition, experimental metal alloy combinations for interfacing through traditional soldering have been reported [29,30]. Although synthesis of CNTs at temperatures as low as $350{ }^{\circ} \mathrm{C}$ have been accomplished, increasing their density has shown itself to be a challenge [31-33]. In general, interfacing metals with organic molecules or solvents is a major challenge in material development, especially for CNTs because of issues such as the nanotube dimensions, orientation, and wettability. In most efforts to grow CNTs directly on metal substrates, the CNT quality has been compromised by attempts to reduce the temperature and oxide catalyst support thickness $[27,28]$. Other interfacing approaches such as the self-assembly of monolayers [14,34], soldering [29,30], colloidal metallic pastes [35], and electrodeposition have also been employed, but they all have shown limitations.

Despite almost three decades of intense CNT research, most synthesis methods have failed to meet expectations due to challenges associated with CNT synthesis, controlling CNT type, chirality and diameter [36-39]. Unsatisfactory results have been achieved for several electrical and thermal applications based on current CNT assemblies. One reason for this poor performance includes the ability to assemble CNTs into macroscopic fibers and films with similar properties $[40,41]$, as well as the assumption that traditional macroscopic contact interfacing methods are sufficient to connect most carbon nanomaterials to metal surfaces. High thermal and electrical interface resistances have been reported between CNTs and their contacts, owing to weak adhesion of the nanoscale paths $[14,34,42,43]$. Interfaces between dissimilar materials often control phonon and electron transport, especially at the nanoscale level where the importance of the interfaces relative to bulk material properties is substantially increased $[42,44,45]$. CNTs, like most nanomaterials, require a metal support that can efficiently harvest electrons and thus take advantage of their physical properties [21,46]. Notably, short covalently bonded organic molecules at the interface can dramatically increase adhesion between CNT arrays and noble metal contacts, resulting in an approximately sixfold reduction in the thermal interface resistance [14].

Because of their geometrical shape, the conducting properties of CNTs depend on their orientations in assemblies, with true physical properties being lost at the interfaces between the anisotropic nanotubes and metal substrates [47-49]. The electrical conductance of a CNT is closely related to its orientation and interface contact [50]. Based on extensive work with highly ordered pyrolytic graphite, the basal and edge plane reactivities [51] and the electrochemical behavior of CNTs have been shown to differ [52,53]. Various reports have indicated that the edge planes of CNTs have higher electron transfer rates than the basal planes $[51,53,54]$. Furthermore, the intrinsic metallic or semiconducting properties of CNTs, as well as their single- or multi-walled nature, can lead to discrepancies in the measured electron transfer rates. Theoretical studies on simulating the interface between individual CNTs and metals have found great resistance at the metal-CNT interfaces with simple contact [55-57]. More recently, systematic methods to control, engineer, and study open-ended CNTs have been developed, and the applications of CNT tip reactions have led to the development of highly sensitive sensors [35,58].

This paper reports a method for chemically joining open-ended CNTs to metal substrates $(\mathrm{Cu}$ or $\mathrm{Pt}$ ). For this purpose, high-density CNTs (HD-CNTs) with functionalized open ends were positioned orthogonally to a metal substrate. The metal substrate was also functionalized with suitable organic linkers to promote a chemical junction between the carboxylic and amine groups at the ends of the CNTs and metal substrates, respectively. Successful cross-linking between the CNTs and the linkers on the metal surface was demonstrated via conductivity measurements and electrochemical characterization. 


\section{Materials and Methods}

\subsection{Materials}

CNTs were synthesized as vertically aligned arrays that would allow assembly into fibers or threads (Figure 1A). Due to its self-assembly capabilities, this type of vertically aligned CNT is also called spinnable or drawable. The CNTs, which had lengths of approximately $400 \mu \mathrm{m}$, were vertically aligned in a forest format. The catalyst film thickness, precursors, and CNT synthesis parameters have been published by our group elsewhere [41]. The as-synthesized CNT arrays were completely detached from the substrate during synthesis to eliminate catalyst contamination, and the CNT fibers with a 70- $\mu$ m diameter were spun and subsequently densified with acetone before embedding in a polymer.
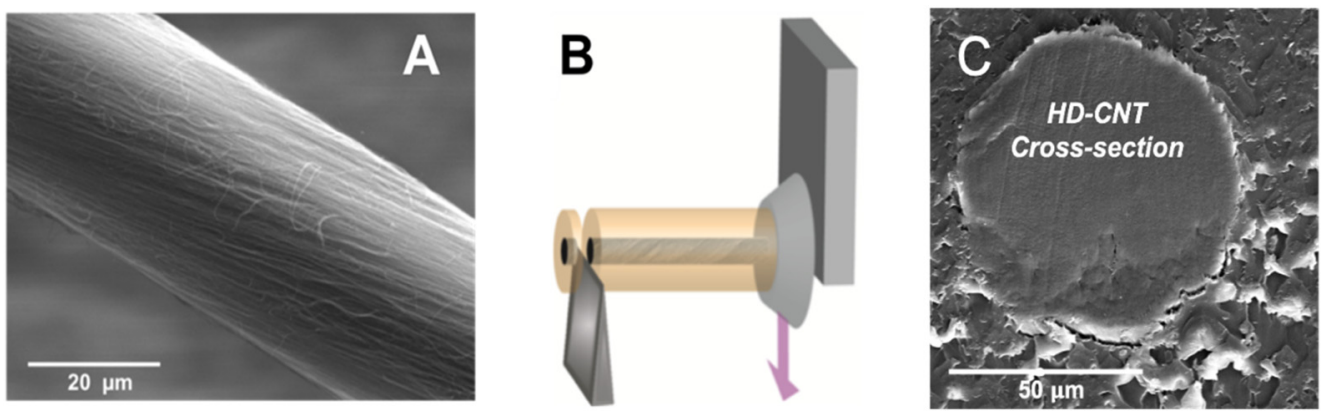

Figure 1. Characterization and fabrication of HD-CNT. (A) SEM image of a CNT fiber. (B) CNT fiber encapsulation within a polymer and subsequent sectioning. (C) SEM image of a cross-section of the resulting HD-CNT.

Lithium trifluoromethanesulfonate $\left(\mathrm{CF}_{3} \mathrm{SO}_{3} \mathrm{Li}, 95 \%\right)$ was obtained from Ambeed Inc., sodium nitrite $\left(\mathrm{NaNO}_{2}, 99.4 \%\right)$ was obtained from Chem-Impex International Inc., and hexaammineruthenium(III) chloride $\left(\left[\mathrm{Ru}\left(\mathrm{NH}_{3}\right)_{6}\right] \mathrm{Cl}_{3}, 98 \%\right)$ was obtained from Acros Organics. Sodium acetate (NaOAc. $\left.3 \mathrm{H}_{2} \mathrm{O}, 99.0 \%\right)$ and acetic acid $\left(\mathrm{CH}_{3} \mathrm{COOH}, 99.0 \%\right)$ were purchased from Fisher Scientific. Ethylenediamine (99\%), nitric acid $\left(\mathrm{HNO}_{3}, 95 \%\right)$, hydrochloric acid $(\mathrm{HCl}, 37 \%)$, potassium chloride $(\mathrm{KCl}, 99 \%)$, acetone $(99.7 \%)$, ethanol $(99.8 \%)$, potassium ferricyanide $\left(\mathrm{K}_{3}\left[\mathrm{Fe}(\mathrm{CN})_{6}\right], 99 \%\right)$, lead standard $\left(1000 \mathrm{mg} \mathrm{L}^{-1}\right)$, and acetonitrile (99\%) were purchased from Sigma-Aldrich and used as received. EMBed812 resin was purchased from Electron Microscopy Sciences and mixed following the manufacturer's instructions.

\subsection{Carbon Nanotube Fiber Cross-Section Preparation and Bonding to Metal}

To position enough CNTs orthogonal to the substrates, we employed aligned CNTs assembled within a fiber section. Embedding or encapsulating sections of aligned CNTs within polymers allowed the fabrication of HD-CNT assemblies, which was accomplished using a clear polymer (Embed-812) [58]. Ultramicrotoming of the polymer-embedded CNT fibers was performed to create open-ended HD-CNTs within a $40-\mu \mathrm{m}$ thick film (Figure 1B), where the CNTs passed through the film and had an open end on both sides of the film. A scanning electron microscopy (SEM) image of the HD-CNT cross-section for a single CNT fiber is shown in Figure 1C. This process gave access to the open ends of the CNTs while limiting the reactions at their cross-sections, as published by our group elsewhere $[35,58]$. Additionally, embedding in a polymer maintained the CNTs in a vertical position and allowed convenient manipulation, including applying pressure to create intimate contact with metal surfaces for bonding. The open ends of the fiber cross-sections were treated with $\mathrm{HNO}_{3}(2 \mathrm{M})$ at $70{ }^{\circ} \mathrm{C}$ for $24 \mathrm{~h}$ for additional functionalization with the carboxylic groups. 


\subsection{Modification of the Metal Surface}

$\mathrm{Cu}$ and $\mathrm{Pt}$ metal sheets were polished with 600-grit silicon carbide paper followed by crystal polishing paper, sonicated in acetone for $30 \mathrm{~min}$, and then washed with deionized water and isopropyl alcohol before the electrochemical-chemical reaction. For CNT-Cu bonding, it was important to minimize $\mathrm{Cu}$ oxidation; therefore, acetic acid treatment was employed. The 4-aminophenyl diazonium cations generated in situ by the reaction of $p$-phenylenediamine and $\mathrm{NaNO}_{2}$ in an acidic medium were used as the precursor, which were known to reduce to a highly reactive radical capable of bonding to metal surfaces (Figure 2A) [59-61]. For CNT-Pt bonding, ethylenediamine was electrochemically grafted on the Pt surface in acetonitrile as a solvent similar to that reported by Segut et al. (Figure 2B) [62]. Herlem et al. has used a similar electrochemical grafting reaction to modify metal electrodes with ethylenediamine $[63,64]$. Cyclic voltammetry at a scan rate of $50 \mathrm{mV} \mathrm{s}^{-1}$ was used to identify the oxidative grafting of ethylenediamine on a Pt sheet electrode in acetonitrile with an Ag pseudo-reference electrode (Figure S1).
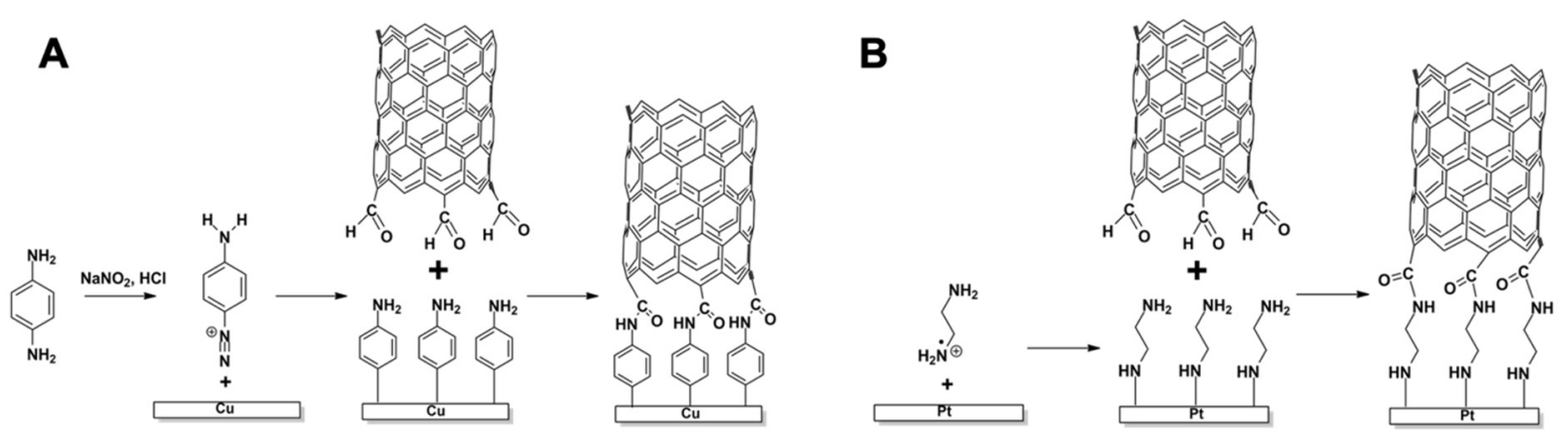

Figure 2. Proposed mechanism for the chemical bond formation between metals and open-ended CNTs. (A) In situ generation and attachment of an amine functional group to a $\mathrm{Cu}$ surface and subsequent bonding to a carboxylic acid functional group at the open end of a CNT. (B) Electrochemical attachment of ethylenediamine to a Pt surface and subsequent bonding of the amine end to the carboxylic acid at the open ends of the CNTs.

Subsequently, the amine-grafted metal surface and carboxylic-functionalized HD-CNT cross-section within the film were clamped together and heated to $\sim 80^{\circ} \mathrm{C}$ to promote a reaction between the surface functional groups [14].

\subsection{CNTs Bonded to Metal as a Working Electrode}

Electrochemical characterization and electrical conductivity measurements of the chemically bonded CNTs to $\mathrm{Cu}$ metal were performed on electrodes assembled as shown in Figure S2. A single HD-CNT within a film $(\sim 70 \mu \mathrm{m}$ in diameter and $\sim 40 \mu \mathrm{m}$ thick) with open-ended CNTs was connected to a metal and employed as a working electrode. To investigate the stability and electrochemical behavior of the fabricated electrodes, cyclic voltammetry measurements of $\left[\mathrm{Ru}\left(\mathrm{NH}_{3}\right)_{6}\right] \mathrm{Cl}_{3}$ with $0.5 \mathrm{M} \mathrm{KCl}$ as a supporting electrolyte were performed in the potential window from 0.1 to $-0.5 \mathrm{~V}$. Stripping voltammetry is an effective technique for heavy metal detection with various kinds of electrodes. Therefore, stripping analysis was performed for $\mathrm{Pb}^{2+}$ detection in the potential window of $-1.2-0 \mathrm{~V}$, with CNT-Cu chemically bonded electrodes as the working electrode. Commercially available $\mathrm{Pb}\left(\mathrm{NO}_{3}\right)_{2}$ in a $2 \% \mathrm{HNO}_{3}$ solution was used to prepare the $\mathrm{Pb}^{2+}$ solutions in a $0.1 \mathrm{M}$ acetate buffer ( $\mathrm{pH} 4.3$ ) at concentrations of 20-50 ppb, and calibration curves were constructed based on the current intensities recorded for the $\mathrm{Pb}^{2+}$ solutions. The following optimized square wave anodic stripping voltammetry (SWASV) parameters were used: frequency, $15 \mathrm{~Hz}$; amplitude, $0.025 \mathrm{~V}$; deposition potential, $-1.2 \mathrm{~V}$; potential step, $0.004 \mathrm{~V}$; and deposition time, $120 \mathrm{~s}$. The stripping peaks were used to quantify the $\mathrm{Pb}$ concentration. 


\subsection{Instrumentation}

SEM images were recorded using an FEI Apreo scanning electron microscope at acceleration voltages of $5-15 \mathrm{kV}$ to visualize the CNT cross-sections on the metal surfaces. An EDAX elemental analysis detector coupled with the same SEM instrument was used to analyze the atomic compositions of the samples. The Raman spectra of HD-CNTs attached to the metal surface were collected using a Renishaw inVia Raman microscope with a $\mathrm{HeNe}$ laser as the excitation source $(633 \mathrm{~nm})$. FT-IR spectra were collected using a Nicolet 6700 FT-IR instrument to identify the surface functionalization. All electrochemical analyses were performed using a PalmSens3 potentiostat/galvanostat. A three-electrode system was used with a $\mathrm{Ag} / \mathrm{AgCl}$ reference electrode and a Pt wire counter electrode unless otherwise specified.

\section{Results and Discussion}

Freshly microtomed HD-CNTs from the same fiber were functionalized at their open ends. For this purpose, positioning CNTs while maintaining their orientations and protecting their side walls within the assembly was required. We accomplished this by assembling CNTs into macroscopic fibers, where the CNTs had linear orientations and maintain their pristine nature of individual CNTs while their side walls were encapsulated within a polymer $[40,41]$. Aside from protecting the side walls, the encapsulating polymer prepared as film facilitated handling of the microscale HD-CNTs without ever making contact with their open ends. The CNTs in Figure 2A,B illustrate the carboxylic functionalized ends that were employed to react with amino functional groups at the $\mathrm{Cu}$ and $\mathrm{Pt}$ surfaces. In general, covalent bond formation between CNTs and other molecules requires functionalization of the CNT surfaces. A variety of methods for CNT covalent functionalization have been reported, including free radical addition, oxidation, carboxyl-based coupling, fluorination, and addition or substitution reactions. These functionalization reactions have mainly been used to enhance CNT dispersion and compatibility $[65,66]$. Typically, functionalization occurs at the edges of five- or seven-membered ring defects in the basal planes of the CNTs or the tip of the CNTs $[66,67]$. Unfortunately, most of those approaches for functionalization do not allow the positioning of functional groups to be controlled. With the current method, access to all carbon atoms at the open-ended CNTs was made easier, and their complete functionalization would be ideal. To date, quantification of the degree of functionalization has been limited to theoretical studies, where the optimum number of functional groups at the open ends has been determined [68].

The thin films obtained by microtoming that held the HD-CNTs had two important functions: (1) holding the CNTs of a uniform length packed in a cylindrical structure so that the majority of the continuous CNTs pass through the film and have open ends on both sides of the film and (2) covering the sidewalls of the CNTs so that only the open ends of the CNTs are exposed, which allows for chemical modification of the CNT tips, conserving the pristine CNT structure. It was assumed that the number of open-ended CNTs in the HD-CNT film samples were similar because multiple samples could be prepared from the same CNT fiber using microtoming. This is a unique advantage of this approach, because it allows the number of CNTs assembled within a particular fiber to be controlled by limiting the width of the CNT array employed for fiber assembly, as demonstrated previously $[40,69]$. Wet chemistry functionalization is preferential at the open ends of CNTs [70,71]. We selected carboxylic functionalization at the open ends of the CNTs, because carboxylic acid functionalization is a well-established single-step functionalization reaction for CNTs which gives a reactive end for a second molecule attachment [72]. To achieve a high carboxylic density on the CNT open ends, the functionalization time with $\mathrm{HNO}_{3}(2 \mathrm{M})$ was increased to $24 \mathrm{~h}$. The Raman spectra were recorded for CNT crosssections chemically attached to metal surfaces (Figure S3). The peak at $\sim 1585 \mathrm{~cm}^{-1}$ was attributed to the $\mathrm{G}$ band, which originated from the in-plane tangential stretching of the $\mathrm{C}-\mathrm{C}$ bonds in CNTs, whereas the peak at $\sim 1334 \mathrm{~cm}^{-1}$ was attributed to the $\mathrm{D}$ band. The ratio between these bands $\left(I_{\mathrm{G}} / I_{\mathrm{D}}\right)$ indicated a high degree of functionalization. However, 
as the assemblies contained multi-walled CNTs with a relatively high D band intensity, quantitative information about functionalization could not be obtained by comparing only the $\left(I_{\mathrm{G}} / I_{\mathrm{D}}\right)$ ratio. However, EDAX analysis consistently supported an increase in the oxygen content, although by no more than $2 \%$.

Aside from CNT open-end functionalization, suitable functional groups at the metal surface are needed in order to chemically link CNTs to metal surfaces. Metal surface functionalization was accomplished using organic radical metal reactions, also known as grafting. To realize bond formation between a carboxylic functionalized CNT tip and a metal, the metal surface was functionalized with the amine groups (Figure 2A,B). Amine functionalization of the $\mathrm{Cu}$ surface was achieved using a spontaneous reaction between a $p$-aminobenzenediazonium cation and $\mathrm{Cu}$ metal, which left the chemically bonded aminophenyl group on the $\mathrm{Cu}$ surface in a similar manner to that reported by Chamoulaud et al. [60]. In contrast, the Pt surface was electrografted by short ethylamine groups with ethylenediamine as described in the experimental section. Then, to promote bond formation between the CNTs and the organic groups grafted on the metal surfaces, functionalized open-ended CNTs were pressed against the metal surfaces using small magnetic discs during the reaction while the temperature was increased. The electrografted organics on metals acted as linkers to join the open-ended CNTs. This type of metal functionalization using reactive organic molecules is a topic of intense research. Several metals, including stainless steel, $\mathrm{Ni}, \mathrm{Au}$, and polycrystalline $\mathrm{Cu}$, have been functionalized using aryl diazonium cations $\left(\mathrm{R}_{-} \mathrm{N}_{2}{ }^{+}\right)$. Anthracene, anthraquinone, and hydroquinone have been covalently bonded to metal surfaces, presumably through the formation of carbides and nitrides [73].

As shown by the reaction mechanism in Figure 2A, upon reduction, the diazonium salts generated strong radical species that could bond to metal and carbon surfaces [74]. $p$ Phenylenediamine reacted with $\mathrm{NaNO}_{2}$ and $\mathrm{HCl}$ to generate the $p$-aminobenzenediazonium cation in situ as described by Lyskawa et al., which was spontaneously grafted onto the $\mathrm{Cu}$ surface to generate aminophenyl groups [75]. Spontaneous grafting will occur if the surface of the substrate is sufficiently reduced to convert the diazonium salt to a radical that can react with the same surface. In addition, there is the potential to be applied to promote a reaction between $p$-aminobenzenediazonium cations and metals such as $\mathrm{Pt}$ and $\mathrm{Au}$ [76]. The grafted aminophenyl groups on the $\mathrm{Cu}$ surface reacted with the carboxylic groups on the CNT open ends, which were obtained by CNT oxidation. Although the amine-carboxylic coupling reactions employed in this work were aimed at covalent bond formation between functional groups at the metal surface and open-end CNTs, the nature of the resulting bonding was not possible to determine. As a result of those challenges, "chemical bond" is used throughout the text instead of covalent bonding. The expected amide formation resulting from amine-carboxylic coupling is localized between macroand micro-structures, where the access is limited.

Covalent bonding of ethylenediamine on the Pt surface was accomplished via electrografting (Figure 2B). The highly reactive ethylenediamine radical is known to attack metal surfaces, leaving an amine functional group available for subsequent reactions. Similar bonding has been reported by Adenier et al., and a mechanism of bond formation between metals and organic moieties has been reported [73]. Upon the electrochemical oxidation of primary amines using Pt metal as a working electrode, bond formation and the growth of a continuous film was observed. Unfortunately, due to the polymerization of ethylenediamine on the working electrode surface, more than a monolayer buildup was observed, which resulted in an electrical passivation of the metal surface. Although further investigations to identify the thickness of the interface between Pt and the CNTs are pending, bonding of ethylenediamine has been confirmed by several other researchers.

FT-IR spectral analysis on the functionalized $\mathrm{Cu}$ supported the organic moiety grafting to the $\mathrm{Cu}$ surface. Spectra were recorded before and after grafting on the $\mathrm{Cu}$ surface to identify the functional groups attached to the metal surface. Furthermore, the spectra after sonication of the samples to determine the bonding strength between grafted 
organic groups and the metal surface were collected (Figure 3). The FT-IR spectrum of the aminophenyl-grafted $\mathrm{Cu}$ surface exhibited a weak broad peak at $\sim 3400 \mathrm{~cm}^{-1}$, which was attributed to $\mathrm{N}-\mathrm{H}$ stretching [77]. A similar broad peak has been observed in the FT-IR spectra of polymerized diamines, whereas crystalline diamines exhibit sharp peaks in this region $[77,78]$. Clear peaks were observed in the $1350-1610 \mathrm{~cm}^{-1}$ region, specifically at 1496,1511 , and $1608 \mathrm{~cm}^{-1}$, which were attributed to $C=C$ bond stretching in the aromatic rings $[60,77,78]$. The band observed at $1259 \mathrm{~cm}^{-1}$ was attributed to $\mathrm{C}-\mathrm{NH}_{2}$ stretching, whereas that at $1178 \mathrm{~cm}^{-1}$ was attributed to $\mathrm{CH}$ bending. The peak at 831 $\mathrm{cm}^{-1}$ corresponded to $\mathrm{CH}$ out-of-plane bending, and that at $630 \mathrm{~cm}^{-1}$ could correspond to ring deformation [78]. The observation of peaks around $2300 \mathrm{~cm}^{-1}$ indicated the presence of trace $\mathrm{CO}_{2}$ in the atmosphere. No peak corresponding to the $\mathrm{N} \equiv \mathrm{N}$ stretching mode of diazonium at $2280 \mathrm{~cm}^{-1}$ was observed, which supports the proposed metal-organic reaction [60]. The peak intensities decreased as the reaction temperature decreased from 65 to $25{ }^{\circ} \mathrm{C}$ on the FTIR peaks in Figure 3, which suggests that this grafting reaction is dependent on the temperature. Alternatively, this behavior could be due to multilayer formation, owing to the reactions between in situ generated diazonium molecules. For comparison purposes, the FTIR of pure 4-phenylenediamine was recorded (Figure S4), where the main features discussed in Figure 3 are also visible. The covalent nature of $\mathrm{Cu}-\mathrm{C}$ bonds has been reported by McCreery et al., as has multilayer formation on $\mathrm{Cu}$ substrates via diazonium salt-Cu metal reactions [61]. However, in our work, strong peak intensities were observed after sonication, which suggests the formation of strong bonds between the metal surface and the organic groups. Furthermore, an EDAX analysis (not shown) indicated that the atomic percentage of $C$ increased upon grafting of the organic groups to the metal surface.

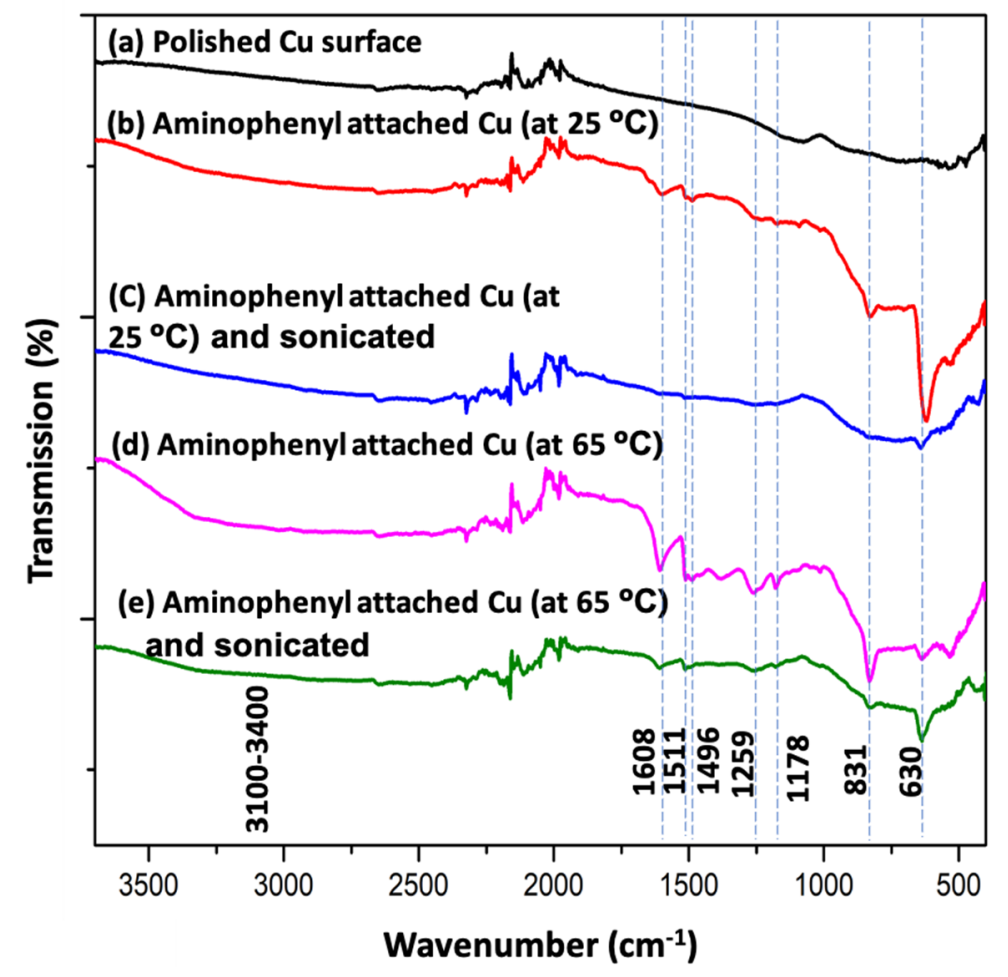

Figure 3. FTIR spectra of organic grafted Cu surface. Normalized FTIR spectra of (a) polished Cu surface, (b) aminophenyl group attached to $\mathrm{Cu}$ surface at $25^{\circ} \mathrm{C},(\mathbf{c})$ aminophenyl group attached to $\mathrm{Cu}$ surface at $25^{\circ} \mathrm{C}$ after sonication, (d) aminophenyl group attached to $\mathrm{Cu}$ surface at $65^{\circ} \mathrm{C}$, and (e) aminophenyl group attached to $\mathrm{Cu}$ surface at $65^{\circ} \mathrm{C}$ after sonication.

As shown in Figure 4A, vertically standing CNTs bonded to Cu metal were obtained from promoting the bond formation between the aminophenyl groups grafted on the metal 
surface and the oxidized CNT open ends. Afterward, the embedding polymer around the HD-CNTs was physically removed using forceps while the CNTs remained anchored on the metal surface. The forceful removal of the polymer appeared to tear the CNTs at the outer surface of the HD-CNTs, but the number of removed CNTs was minimal considering the large number of them on the cylindrical structure that remained standing (Figure 4A). The three-dimensional nature of the assembly was clearly observed, and the interface between the CNTs and the $\mathrm{Cu}$ metal surface is visible in Figure 4B. Similar attempts with physisorbed embedded CNTs typically removed both the polymer and the CNTs at once, suggesting that the chemical bonding to the metal substrate in the HD-CNT samples was extremely strong for the cross-linked HD-CNTs compared with simple adhesion. The interface between the CNTs and the $\mathrm{Cu}$ substrate is shown at a higher magnification in Figure $4 \mathrm{~B}$, and the connections joining the CNT bundles to the $\mathrm{Cu}$ surface are clearly visible. Figure $4 \mathrm{~B}$ also displays the surface of the $\mathrm{Cu}$, where a rough coating-like surface is visible, suggesting that more than a monolayer of aminophenyl was present after grafting, also supporting the FT-IR spectrum in Figure 3. Ethylenediamine and p-phenylenediamine were both employed to functionalize the metal surface, but due to its electron-rich and electrically conductive nature, $p$-phenylenediamine is preferred.
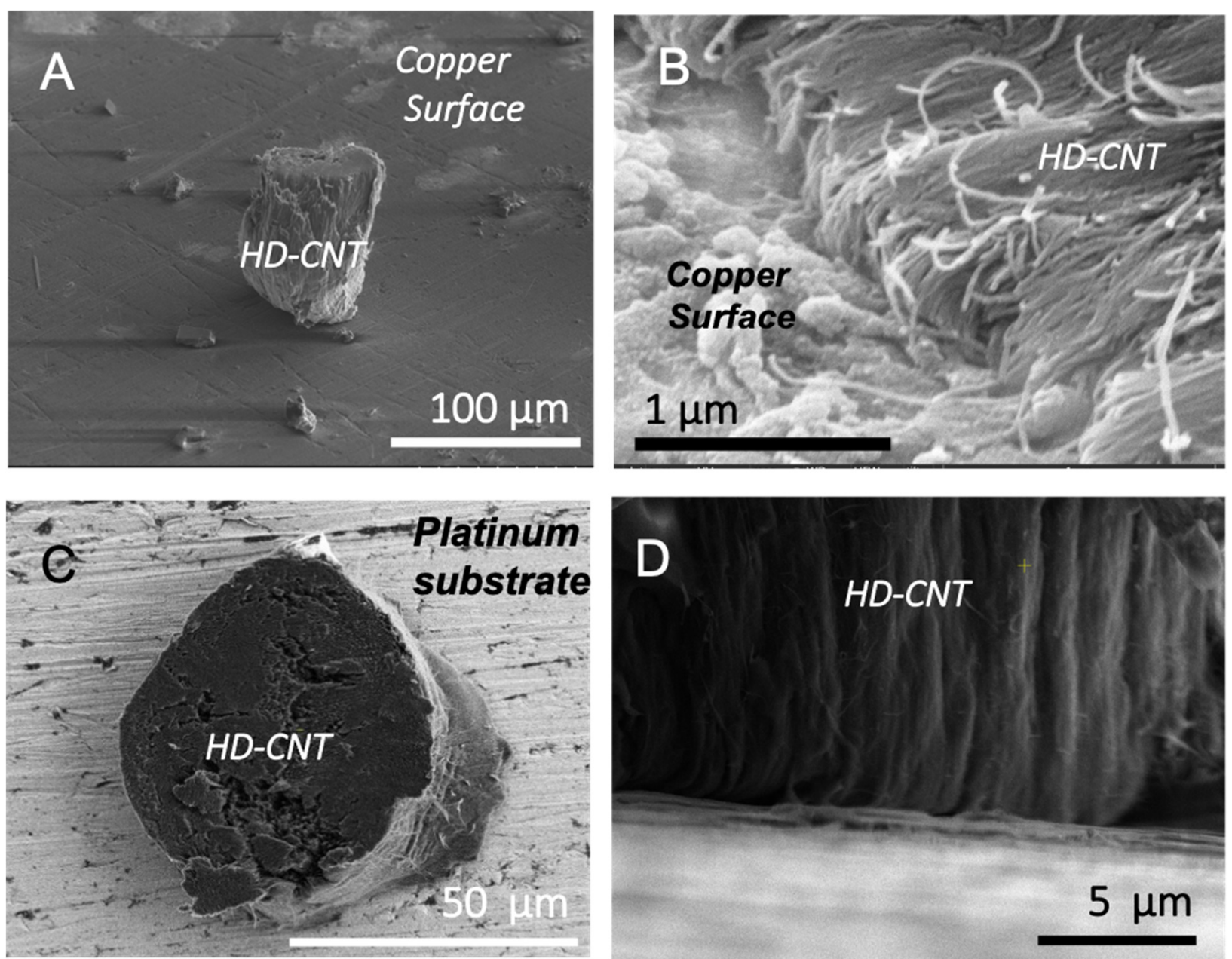

Figure 4. SEM images of HD-CNTs bonded to a solid $\mathrm{Cu}$ and Pt surfaces after removing the encapsulating polymer. (A) Low-magnification and (B) high-magnification images showing the three-dimensional nature of the CNTs assembled on the $\mathrm{Cu}$ surface. (C) Low magnification and (D) high magnification of CNTs connected to the metal Pt surface.

Similarly, a cylindrical structure of vertically oriented CNTs remained attached to the flat Pt surface after removing the encapsulating polymer (Figure 4C), which suggests that the interaction between the CNTs and $\mathrm{Pt}$ was also strong. The junction between the $\mathrm{Pt}$ 
surface and the CNTs is displayed in Figure 4D. Despite the roughness of the Pt metal surface, the pressure applied to the HD-CNTs during the reaction between the amine and carboxylic groups was sufficient to connect the CNTs to the Pt substrate via linker molecules.

Additionally, after sonication of the $\mathrm{Cu}$ metal substrate with bonded HD-CNTs, some CNT fragments remained on the metal substrate, as observed by SEM (Figure S5). These CNT fragments were located in the area where the HD-CNTs were originally bonded to the $\mathrm{Cu}$ substrate, suggesting that the degree of bonding between CNTs was extremely strong, but not all CNTs were chemically bonded to the $\mathrm{Cu}$. The presence of CNTs on the metal surface after sonication was also confirmed by Raman spectroscopy, as the G and D bands typical of CNTs were observed. However, the fact that only small bundles of CNTs remained after sonication suggests non-uniformity among the CNTs bonding to the $\mathrm{Cu}$ surface. This was possible due to the roughness of the $\mathrm{Cu}$ substrate and lack of atomically flat HD-CNT cross-sections. In a similar experiment with a Pt substrate, it was difficult to locate clean CNTs due to some coating that occurred after sonication.

Successful metal-CNT bonding was also confirmed using electrochemical methods. CNT-Cu bonded electrodes were prepared in which only the HD-CNT cross-section was exposed to the electrolyte. Typically, $\mathrm{Ru}\left(\mathrm{NH}_{3}\right)_{6}{ }^{2+/ 3+}$ is a good indicator for carbon electrode surfaces and electrolyte interactions. The absence of sharp oxidation or reduction peaks in the background cyclic voltammogram $(\mathrm{CV})$ confirmed the inert nature of the tailored electrode surface for oxidation or reduction in the presence of a supporting electrolyte (Figure 5), which is characteristic of CNT cross-sectional electrodes. This observation suggests that electron transfer at the working electrode can only occur through the CNT cross-sections available to the solution. In addition, the interface between the $\mathrm{Cu}$ metal and HD-CNTs must be electrically conductive to allow electron transfer between them. Furthermore, the observation of characteristic oxidation and reduction peaks in the cyclic voltammogram of the ruthenium redox couple confirmed the electrically conductive nature of the CNT-Cu bonded electrode, attributable to a stable electrically conductive joint between the CNT cross-section and the metal substrate (Figure 5).

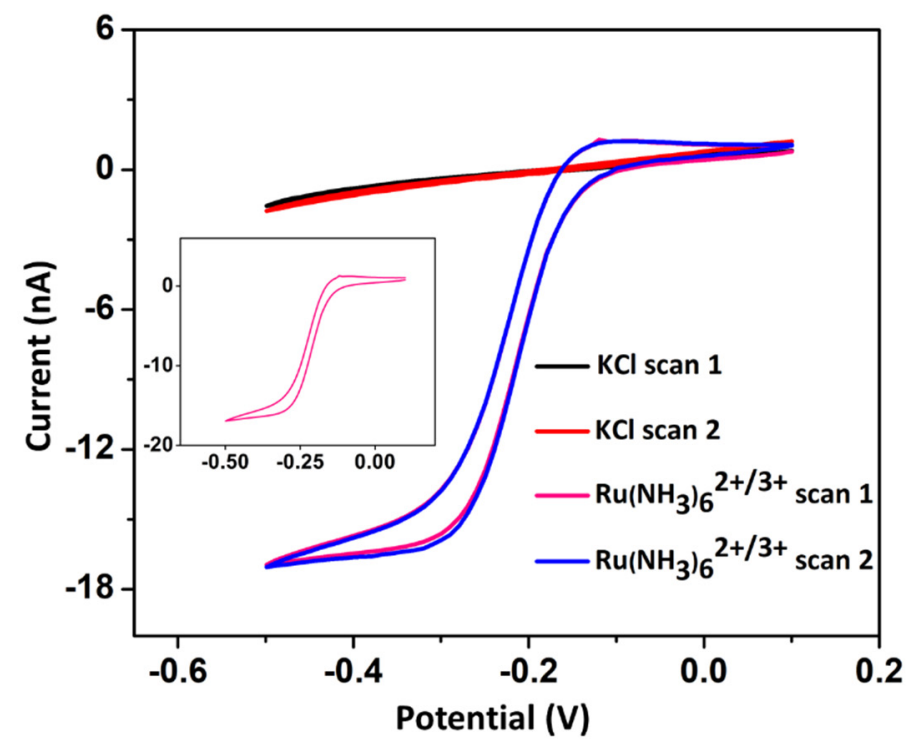

Figure 5. Electrochemical characterization of CNTs bonded to metal surfaces. Cyclic voltammograms of CNTs bonded to $\mathrm{Cu}$ as the working electrode: red and black lines = background response in $0.5 \mathrm{M}$ $\mathrm{KCl}$ aqueous solution; pink and blue lines (pink barely visible under the blue) = response for $2 \mathrm{mM}$ $\mathrm{Ru}\left(\mathrm{NH}_{3}\right)_{6}{ }^{2+/ 3+}$ in $0.5 \mathrm{M}$ aqueous $\mathrm{KCl}$ solution. The pink line corresponding to $2 \mathrm{mM} \mathrm{Ru}\left(\mathrm{NH}_{3}\right)_{6}{ }^{2+/ 3+}$ in $0.5 \mathrm{M}$ aqueous $\mathrm{KCl}$ has been replotted as an inset to make it visible.

As a benchmark, the electrochemical performance of freshly microtomed HD-CNTs connected to a metal surface using colloidal Ag paste was compared with that of CNTs co- 
valently bonded to the metal surface. In addition, a physiadsorbed HD-CNT cross-section to $\mathrm{Cu}$ metal was also characterized, but the results were significantly inconsistent. The covalently bonded to $\mathrm{Cu}$ and $\mathrm{Pt}$ and $\mathrm{Ag}$ paste-connected CNTs displayed very similar $\mathrm{CV}$ characteristics, suggesting good electrical contact between the CNTs and metals. The contact effectiveness with the metal surface was evaluated using cyclic voltammetry and the electroactive surface area, as determined using the Randles-Sevcik equation [79], which was similar to the geometrical surface area. To determine the heterogeneous electron transfer rates $\left(k^{\circ}, \mathrm{cm} \mathrm{s}^{-1}\right)$, cyclic voltammetry experiments were performed in $2 \mathrm{mM}$ of $\mathrm{Ru}\left(\mathrm{NH}_{3}\right)_{6}{ }^{2+/ 3+}$ with $0.5 \mathrm{M} \mathrm{KCl}$ as a supporting electrolyte in distilled water at scan rates of $10-20 \mathrm{mV} \mathrm{s}^{-1}$. As can be seen in Figure 5, the covalently bonded HD-CNTs displayed a sigmoidal steady state limiting current with a magnitude of $\sim 17 \mathrm{nA}$. These are typical characteristics of hemispherical diffusion at a reduced diameter of microelectrodes. The steady state behavior of both redox species at a scan rate of $10 \mathrm{mV} \mathrm{s}^{-1}$ was determined in a similar manner to our previous work, in which CNTs were connected with Ag paint [58]. The peak current response increased as the scan rate increased, further confirming that radial diffusion occurred at the electrode-electrolyte interface [58]. In addition, the electrode response was evaluated at increasing potentials. The electrodes generated reproducible cyclic voltammetry responses in the potential range from $+1 \mathrm{~V}$ to $-1.25 \mathrm{~V}$. Furthermore, an $E_{1 / 4}-E_{3 / 4}$ wave potential difference of $59 \mathrm{mV}$ was observed for the open-ended CNTs connected through covalent bonds to the metal.

Theoretical studies and a few experimental reports have shown the enormous potential of open-ended CNTs connected to metals $[50,55,58,80]$. Electrical resistivity of $9 \times 10^{-7} \Omega \mathrm{m}$ was reported for CNTs connected to Au, which is two orders of magnitude higher than that achieved using simple contact, conducting almost as much as $\mathrm{Cu}$ might [46]. To evaluate the impact of covalent bonding HD-CNT to metal, the electrical resistances of the covalently bonded CNT cross-section electrodes were determined using a sensitive picoamp meter. The covalently bonded CNT cross-sections were compared to connections made using colloidal Ag paint and simple pressure contact (physiadsorbed HD-CNTs). In all cases, sealing with epoxy was applied in a similar manner to all covalently bonded HDCNTs. The average resistance measured for covalently bonded CNTs was $305 \Omega$, whereas that for colloidal Ag-connected CNTs was $151 \Omega$, and the pressure contact samples gave inconsistent measurements throughout five different samples. The difference, although minimal, was attributed to the nanoscale roughness of the metal surfaces and required optimization in order to guarantee that all dangling carbons at the circumference of the open ends were bonded. Although our results are not close to the theoretical published results, to the best of our knowledge, this is the first attempt to covalently bond open-ended HD-CNTs to metal substrates.

Finally, the sensing capabilities of the CNTs covalently bonded to metal surfaces were demonstrated by detecting $\mathrm{Pb}^{2+}$ ions in an aqueous solution (Figure 6). The fabricated CNT-Cu bonded electrodes were able to detect low concentrations of $\mathrm{Pb}^{2+}$, and a linear relationship was observed between the $\mathrm{Pb}^{2+}$ concentration and the peak current response $\left(R^{2}=0.9973\right)$. These results are extremely important because they confirm the possibility of using CNTs bonded to a $\mathrm{Cu}$ metal surface via wet chemistry functionalization to develop electrochemical sensors for heavy metals. The observed behavior suggests that effective electrical contacts can be created at low temperatures, providing an alternative to surface melting using noncontact induction heating, which has previously been employed to achieve CNTs bonded to Au metal for microelectronics [46]. 


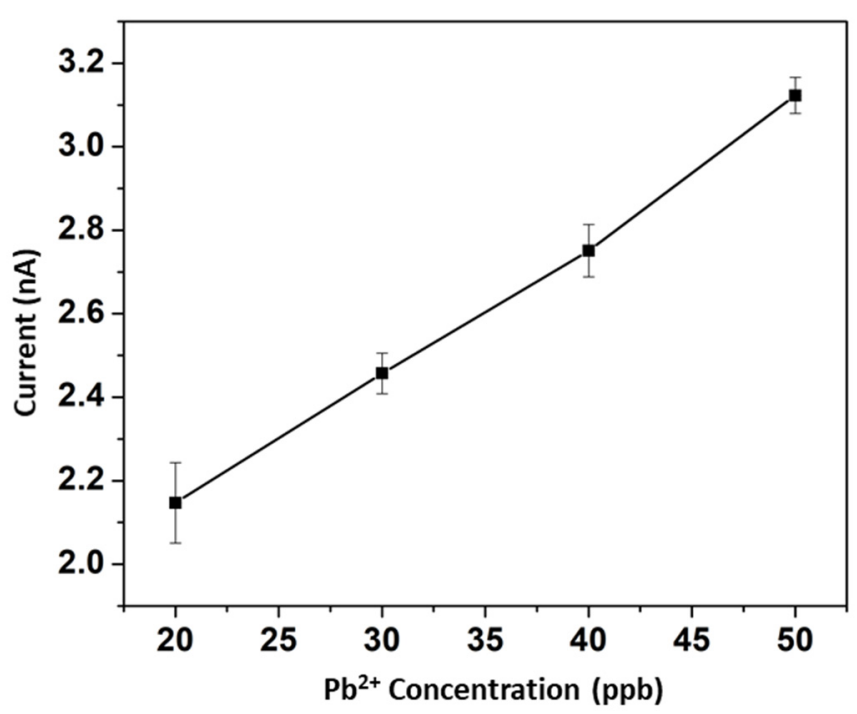

Figure 6. Sensing capability of $\mathrm{CNTs}$ bonded to metal surfaces for $\mathrm{Pb}^{2+}$ detection. The peak current response from the SWASV analysis was extracted to construct a calibration curve using CNTs bonded to $\mathrm{Cu}$ as the working electrode.

The scope of this work was limited to $\mathrm{Cu}$ and Pt surfaces, but more metals should be explored for comparison purposes. In particular, owing to their broad potential industrial applications, $\mathrm{CNTs}$ bonded to $\mathrm{Cu}$ and $\mathrm{Al}$ are expected to be most relevant. Metals that form more bonds during metal grafting should maximize the number of bonds formed with dangling functional groups on open-ended CNTs. According to theoretical studies and experimental reports, $\mathrm{N}$ - and $\mathrm{C}$-based linkers on metal substrates should be advantageous, and such molecules have already been shown to form nitrates and carbides $[73,81]$. For $\mathrm{N}-\mathrm{Cu}$ bonding, we selected oxidative electrografting for amine functionalization, preferentially with primary amines [82]. In addition, we selected spinnable CNTs to prepare HD-CNT assemblies because of their simplicity. Furthermore, assembling fibers from spinnable CNTs is among the cleanest methods because catalyst particles can be removed during synthesis [41] and no further processing is required, which minimizes potential contamination.

\section{Conclusions}

Chemical bond formation between CNTs and metal supports at low temperatures provide ideal contact for efficient electron transfer between metals and CNTs, thus opening a path for CNT application in electronics. This approach provided control of both the CNT orientation and the chemistry at the CNT-metal interface. Due to the high density and vertical arrangement of the CNTs, the bonded CNTs are suitable to work as interconnects. The successful covalent bonding of HD-CNT assemblies to $\mathrm{Cu}$ and $\mathrm{Pt}$ was confirmed, and high-resolution SEM revealed the nature of their connections. Furthermore, electrochemical characterization demonstrated the conductivity and sensing capabilities of the new metalCNT interfaces. Appropriate functionalization at the opposite ends of the CNTs will allow the development of highly sensitive electrochemical sensors, realizing efficient charge transfer to the solution and tissue and producing high-energy-density and high-powerdensity energy storage devices.

Supplementary Materials: The following are available online at https:/ / www.mdpi.com/article/ 10.3390/app11209529/s1, Figure S1: Cyclic voltammograms recorded on a standard Pt electrode, Figure S2: Schematic showing the process used to fabricate the CNT bonded to metal electrode, Figure S3: Raman spectra of Cu surface after CNT attachment, Figure S4: FTIR spectra of pure 4-phenylenediamine, Figure S5: High magnified SEM images of CNT attached Cu metal surface after sonication. 
Author Contributions: Conceptualization, N.T.A.; methodology, N.T.A. and C.P.N.; validation, formal analysis, N.T.A., C.P.N., A.H., C.K.R.; investigation and data curation, C.P.N., A.H., C.K.R. and C.E.R.; writing-original draft preparation, C.P.N. and N.T.A.; writing-review and editing, C.P.N., A.H., C.K.R., C.E.R. and N.T.A.; supervision, project administration, and funding acquisition, N.T.A. All authors have read and agreed to the published version of the manuscript.

Funding: University of Cincinnati, Chemistry Department Professorship.

Acknowledgments: The authors are indebted to professorship start-up funds from the Department of Chemistry at the University of Cincinnati, David Cullen at Oak Ridge National Laboratory for providing some SEM images, and V. Shanov for providing the CNT fiber.

Conflicts of Interest: The authors declare no conflict of interest.

\section{References}

1. Iijima, S. Helical microtubules of graphitic carbon. Nature 1991, 354, 56-58. [CrossRef]

2. Monthioux, M.; Kuznetsov, V.L. Who should be given the credit for the discovery of carbon nanotubes? Carbon N. Y. 2006, 44, 1621-1623. [CrossRef]

3. Baughman, R.H.; Zakhidov, A.A.; de Heer, W.A. Carbon nanotubes-The route toward applications. Science 2002, 297, 787-792. [CrossRef] [PubMed]

4. Behabtu, N.; Young, C.C.; Tsentalovich, D.E.; Kleinerman, O.; Wang, X.; Ma, A.W.K.; Bengio, E.A.; Ter Waarbeek, R.F.; de Jong, J.J.; Hoogerwerf, R.E.; et al. Strong, light, multifunctional fibers of carbon nanotubes with ultrahigh conductivity. Science 2013, 339, 182-186. [CrossRef]

5. De Volder, M.F.L.; Tawfick, S.H.; Baughman, R.H.; Hart, A.J. Carbon nanotubes: Present and future commercial applications. Science 2013, 339, 535-539. [CrossRef] [PubMed]

6. Yu, M.F.; Lourie, O.; Dyer, M.J.; Moloni, K.; Kelly, T.F.; Ruoff, R.S. Strength and breaking mechanism of multiwalled carbon nanotubes under tensile load. Science 2000, 287, 637-640. [CrossRef]

7. Ebbesen, T.W.; Lezec, H.J.; Hiura, H.; Bennett, J.W.; Ghaemi, H.F.; Thio, T. Electrical conductivity of individual carbon nanotubes. Nature 1996, 382, 54-56. [CrossRef]

8. White, C.T.; Todorov, T.N. Carbon nanotubes as long ballistic conductors. Nature 1998, 393, 240-241. [CrossRef]

9. Bai, Y.; Zhang, R.; Ye, X.; Zhu, Z.; Xie, H.; Shen, B.; Cai, D.; Liu, B.; Zhang, C.; Jia, Z.; et al. Carbon nanotube bundles with tensile strength over 80 GPa. Nat. Nanotechnol. 2018, 13, 589-595. [CrossRef]

10. Poncharal, P.; Berger, C.; Yi, Y.; Wang, Z.L.; de Heer, W.A. Room temperature ballistic conduction in carbon nanotubes. J. Phys. Chem. B 2002, 106, 12104-12118. [CrossRef]

11. Bachtold, A.; Henny, M.; Terrier, C.; Strunk, C.; Schönenberger, C.; Salvetat, J.P.; Bonard, J.M.; Forró, L. Contacting carbon nanotubes selectively with low-ohmic contacts for four-probe electric measurements. Appl. Phys. Lett. 1998, 73, 274-276. [CrossRef]

12. Kim, P.; Shi, L.; Majumdar, A.; McEuen, P.L. Thermal transport measurements of individual multiwalled nanotubes. Phys. Rev. Lett. 2001, 87, 215502-1-215502-4. [CrossRef] [PubMed]

13. Subramaniam, C.; Yamada, T.; Kobashi, K.; Sekiguchi, A.; Futaba, D.N.; Yumura, M.; Hata, K. One hundred fold increase in current carrying capacity in a carbon nanotube-copper composite. Nat. Commun. 2013, 4, 2202. [CrossRef]

14. Kaur, S.; Raravikar, N.; Helms, B.A.; Prasher, R.; Ogletree, D.F. Enhanced thermal transport at covalently functionalized carbon nanotube array interfaces. Nat. Commun. 2014, 5, 3082. [CrossRef]

15. Milowska, K.Z.; Burda, M.; Wolanicka, L.; Bristowe, P.D.; Koziol, K.K.K. Carbon nanotube functionalization as a route to enhancing the electrical and mechanical properties of Cu-CNT composites. Nanoscale 2019, 11, 145-157. [CrossRef]

16. McIntyre, D.J.; Hirschman, R.K.; Puchades, I.; Landi, B.J. Enhanced copper-carbon nanotube hybrid conductors with titanium adhesion layer. J. Mater. Sci. 2020, 55, 6610-6622. [CrossRef]

17. Sundaram, R.M.; Sekiguchi, A.; Sekiya, M.; Yamada, T.; Hata, K. Copper/carbon nanotube composites: Research trends and outlook. R. Soc. Open Sci. 2018, 5, 180814. [CrossRef]

18. Miura, S.; Yoshihara, Y.; Asaka, M.; Hasegawa, K.; Sugime, H.; Ota, A.; Oshima, H.; Noda, S. Millimeter-tall carbon nanotube arrays grown on aluminum substrates. Carbon N. Y. 2018, 130, 834-842. [CrossRef]

19. Teblum, E.; Noked, M.; Grinblat, J.; Kremen, A.; Muallem, M.; Fleger, Y.; Tischler, Y.R.; Aurbach, D.; Nessim, G.D. Millimeter-tall carpets of vertically aligned crystalline carbon nanotubes synthesized on copper substrates for electrical applications. J. Phys. Chem. C 2014, 118, 19345-19355. [CrossRef]

20. Zhu, W.; Zhang, Y.; Xu, N.; Tan, Y.; Zhan, R.; Shen, Y.; Xu, Z.; Bai, X.; Chen, J.; She, J.; et al. Epitaxial growth of multiwall carbon nanotube from stainless steel substrate and effect on electrical conduction and field emission. Nanotechnology 2017, $28,305704$. [CrossRef] [PubMed]

21. Li, X.; Baker-Fales, M.; Almkhelfe, H.; Gaede, N.R.; Harris, T.S.; Amama, P.B. Rational modification of a metallic substrate for CVD Growth of Carbon Nanotubes. Sci. Rep. 2018, 8, 4349. [CrossRef] [PubMed] 
22. Rao, R.; Pint, C.L.; Islam, A.E.; Weatherup, R.S.; Hofmann, S.; Meshot, E.R.; Wu, F.; Zhou, C.; Dee, N.; Amama, P.B.; et al. Carbon Nanotubes and Related Nanomaterials: Critical Advances and Challenges for Synthesis toward Mainstream Commercial Applications. ACS Nano 2018, 12, 11756-11784. [CrossRef]

23. Esconjauregui, S.; Xie, R.; Guo, Y.; Pfaendler, S.M.-L.; Fouquet, M.; Gillen, R.; Cepek, C.; Castellarin-Cudia, C.; Eslava, S.; Robertson, J. Electrical conduction of carbon nanotube forests through sub-nanometric films of alumina. Appl. Phys. Lett. 2013, 102, 113109. [CrossRef]

24. Zhong, G.; Warner, J.H.; Fouquet, M.; Robertson, A.W.; Chen, B.; Robertson, J. Growth of ultrahigh density single-walled carbon nanotube forests by improved catalyst design. ACS Nano 2012, 6, 2893-2903. [CrossRef]

25. Zhong, G.; Yang, J.; Sugime, H.; Rao, R.; Zhao, J.; Liu, D.; Harutyunyan, A.; Robertson, J. Growth of high quality, high density single-walled carbon nanotube forests on copper foils. Carbon N. Y. 2016, 98, 624-632. [CrossRef]

26. Sugime, H.; Esconjauregui, S.; D'Arsié, L.; Yang, J.; Makaryan, T.; Robertson, J. Growth kinetics and growth mechanism of ultrahigh mass density carbon nanotube forests on conductive Ti/Cu supports. ACS Appl. Mater. Interfaces 2014, 6, 15440-15447. [CrossRef]

27. Lettiere, B.R.; Chazot, C.A.C.; Cui, K.; John Hart, A. High-Density Carbon Nanotube Forest Growth on Copper Foil for Enhanced Thermal and Electrochemical Interfaces. ACS Appl. Nano Mater. 2020, 3, 77-83. [CrossRef]

28. Roumeli, E.; Diamantopoulou, M.; Serra-Garcia, M.; Johanns, P.; Parcianello, G.; Daraio, C. Characterization of vertically aligned carbon nanotube forests grown on stainless steel surfaces. Nanomaterials 2019, 9, 444. [CrossRef] [PubMed]

29. Burda, M.; Lekawa-Raus, A.; Gruszczyk, A.; Koziol, K.K.K. Soldering of Carbon Materials Using Transition Metal Rich Alloys. ACS Nano 2015, 9, 8099-8107. [CrossRef]

30. Ebrahimian, A.; Kokabi, A.H. Friction stir soldering: A novel route to produce graphite-copper dissimilar joints. Mater. Des. 2017, 116, 599-608. [CrossRef]

31. Ma, Z.; Zhou, S.; Zhou, C.; Xiao, Y.; Li, S.; Chan, M. Synthesis of vertical carbon nanotube interconnect structures using CMOS-compatible catalysts. Nanomaterials 2020, 10, 1918. [CrossRef]

32. Vollebregt, S.; Tichelaar, F.D.; Schellevis, H.; Beenakker, C.I.M.; Ishihara, R. Carbon nanotube vertical interconnects fabricated at temperatures as low as $350^{\circ} \mathrm{C}$. Carbon N. Y. 2014, 71, 249-256. [CrossRef]

33. Yokoyama, D.; Iwasaki, T.; Yoshida, T.; Kawarada, H.; Sato, S.; Hyakushima, T.; Nihei, M.; Awano, Y. Low temperature grown carbon nanotube interconnects using inner shells by chemical mechanical polishing. Appl. Phys. Lett. 2007, 91, 263101. [CrossRef]

34. Nylander, A.N.; Fu, Y.; Huang, M.; Liu, J. Covalent anchoring of carbon nanotube-based thermal interface materials using epoxy-silane monolayers. IEEE Trans. Compon. Packag. Manuf. Technol. 2019, 9, 427-433. [CrossRef]

35. Gupta, P.; Tsai, K.; Ruhunage, C.K.; Gupta, V.K.; Rahm, C.E.; Jiang, D.; Alvarez, N.T. True Picomolar Neurotransmitter Sensor Based on Open-Ended Carbon Nanotubes. Anal. Chem. 2020, 92, 8536-8545. [CrossRef] [PubMed]

36. Tu, X.; Manohar, S.; Jagota, A.; Zheng, M. DNA sequence motifs for structure-specific recognition and separation of carbon nanotubes. Nature 2009, 460, 250-253. [CrossRef]

37. Hároz, E.H.; Rice, W.D.; Lu, B.Y.; Ghosh, S.; Hauge, R.H.; Weisman, R.B.; Doorn, S.K.; Kono, J. Enrichment of armchair carbon nanotubes via density gradient ultracentrifugation: Raman spectroscopy evidence. ACS Nano 2010, 4, 1955-1962. [CrossRef]

38. Voggu, R.; Rao, K.V.; George, S.J.; Rao, C.N.R. A simple method of separating metallic and semiconducting single-walled carbon nanotubes based on molecular charge transfer. J. Am. Chem. Soc. 2010, 132, 5560-5561. [CrossRef]

39. Alvarez, N.T.; Li, F.; Pint, C.L.; Mayo, J.T.; Fisher, E.Z.; Tour, J.M.; Colvin, V.L.; Hauge, R.H. Uniform large diameter carbon nanotubes in vertical arrays from premade near-monodisperse nanoparticles. Chem. Mater. 2011, 23, 3466-3475. [CrossRef]

40. Alvarez, N.T.; Miller, P.; Haase, M.R.; Lobo, R.; Malik, R.; Shanov, V. Tailoring physical properties of carbon nanotube threads during assembly. Carbon N. Y. 2019, 144, 55-62. [CrossRef]

41. Alvarez, N.T.; Miller, P.; Haase, M.; Kienzle, N.; Zhang, L.; Schulz, M.J.; Shanov, V. Carbon nanotube assembly at near-industrial natural-fiber spinning rates. Carbon N. Y. 2015, 86, 350-357. [CrossRef]

42. Prasher, R. Nano and Micro Technology-Based Next-Generation Package-Level Cooling Solutions. Intel Technol. J. 2005, 9, 7539-7545. [CrossRef]

43. Sun, S.; Samani, M.K.; Fu, Y.; Xu, T.; Ye, L.; Satwara, M.; Jeppson, K.; Nilsson, T.; Sun, L.; Liu, J. Improving Thermal Transport at Carbon Hybrid Interfaces by Covalent Bonds. Adv. Mater. Interfaces 2018, 5, 1800318. [CrossRef]

44. Prasher, R.; Tong, T.; Majumdar, A. An acoustic and dimensional mismatch model for thermal boundary conductance between a vertical mesoscopic nanowire/nanotube and a bulk substrate. J. Appl. Phys. 2007, 102, 104312. [CrossRef]

45. Chen, J.; Walther, J.H.; Koumoutsakos, P. Covalently Bonded Graphene-Carbon Nanotube Hybrid for High-Performance Thermal Interfaces. Adv. Funct. Mater. 2015, 25, 7539-7545. [CrossRef]

46. Song, X.; Zhao, L.; Wang, J.; Qiao, Y. Ultrafast Bonding of Wafer Scale Vertical Aligned Carbon Nanotubes onto Gold Surface by Induction Heating. Nanosci. Nanotechnol. Lett. 2018, 9, 2083-2087. [CrossRef]

47. Daneshvar, F.; Zhang, T.; Aziz, A.; Sue, H.J.; Welland, M.E. Tuning the composition and morphology of carbon nanotube-copper interface. Carbon N. Y. 2020, 157, 583-593. [CrossRef]

48. Svensson, J.; Campbell, E.E.B. Schottky barriers in carbon nanotube-metal contacts. J. Appl. Phys. 2011, 110, 111101. [CrossRef]

49. Banhart, F. Interactions between metals and carbon nanotubes: At the interface between old and new materials. Nanoscale 2009, 1, 201-213. [CrossRef] 
50. Gao, F.; Qu, J.; Yao, M. Electrical resistance at carbon nanotube/copper interfaces: Capped versus open-end carbon nanotubes. Mater. Lett. 2012, 82, 184-187. [CrossRef]

51. Banks, C.E.; Compton, R.G. New electrodes for old: From carbon nanotubes to edge plane pyrolytic graphite. Analyst 2006, 131, 15-21. [CrossRef]

52. Moore, R.R.; Banks, C.E.; Compton, R.G. Basal plane pyrolytic graphite modified electrodes: Comparison of carbon nanotubes and graphite powder as electrocatalysts. Anal. Chem. 2004, 76, 2677-2682. [CrossRef]

53. Banks, C.E.; Davies, T.J.; Wildgoose, G.G.; Compton, R.G. Electrocatalysis at graphite and carbon nanotube modified electrodes: Edge-plane sites and tube ends are the reactive sites. Chem. Commun. 2005, 7, 829-841. [CrossRef]

54. Chakrabarti, S.; Gong, K.; Dai, L. Structural evaluation along the nanotube length for super-long vertically aligned double-walled carbon nanotube arrays. J. Phys. Chem. C 2008, 112, 8136-8139. [CrossRef]

55. Gao, F.; Qu, J.; Yao, M. Electronic structure and contact resistance at an open-end carbon nanotube and copper interface. Appl. Phys. Lett. 2010, 96, 102108. [CrossRef]

56. Andriotis, A.N.; Menon, M. Structural and conducting properties of metal carbon-nanotube contacts: Extended molecule approximation. Phys. Rev. B Condens. Matter Mater. Phys. 2007, 76, 045412. [CrossRef]

57. Gao, F.; Qu, J.; Yao, M. Effects of local structural defects on the electron transport in a carbon nanotube between Cu electrodes. Appl. Phys. Lett. 2010, 97, 242112. [CrossRef]

58. Gupta, P.; Lazenby, R.A.; Rahm, C.E.; Heineman, W.R.; Buschbeck, E.; White, R.J.; Alvarez, N.T. Electrochemistry of Controlled Diameter Carbon Nanotube Fibers at the Cross Section and Sidewall. ACS Appl. Energy Mater. 2019, 2, 8757-8766. [CrossRef]

59. Mooste, M.; Kibena-Põldsepp, E.; Marandi, M.; Matisen, L.; Sammelselg, V.; Podvorica, F.I.; Tammeveski, K. Surface and electrochemical characterization of aryl films grafted on polycrystalline copper from the diazonium compounds using the rotating disk electrode method. J. Electroanal. Chem. 2018, 817, 89-100. [CrossRef]

60. Chamoulaud, G.; Bélanger, D. Spontaneous derivatization of a copper electrode with in situ generated diazonium cations in aprotic and aqueous media. J. Phys. Chem. C 2007, 111, 7501-7507. [CrossRef]

61. Hurley, B.L.; McCreery, R.L. Covalent Bonding of Organic Molecules to Cu and Al Alloy 2024 T3 Surfaces via Diazonium Ion Reduction. J. Electrochem. Soc. 2004, 151, B252. [CrossRef]

62. Segut, O.; Herlem, G.; Lakard, B.; Blondeau-Patissier, V.; Nardin, M.; Gree, S.; Rauch, J.Y. Electrochemically deposited polyethyleneimine films and their characterization. Synth. Met. 2010, 160, 1359-1364. [CrossRef]

63. Herlem, G.; Goux, C.; Fahys, B.; Dominati, F.; Gonçalves, A.M.; Mathieu, C.; Sutter, E.; Trokourey, A.; Penneau, J.F. Surface modification of platinum and gold electrodes by anodic oxidation of pure ethylenediamine. J. Electroanal. Chem. 1997, 435, 259-265. [CrossRef]

64. Herlem, G.; Reybier, K.; Trokourey, A.; Fahys, B. Electrochemical Oxidation of Ethylenediamine: New Way to Make Polyethyleneimine-Like Coatings on Metallic or Semiconducting Materials. J. Electrochem. Soc. 2000, 147, 597. [CrossRef]

65. Wepasnick, K.A.; Smith, B.A.; Schrote, K.E.; Wilson, H.K.; Diegelmann, S.R.; Fairbrother, D.H. Surface and structural characterization of multi-walled carbon nanotubes following different oxidative treatments. Carbon N. Y. 2011, 49, 24-36. [CrossRef]

66. Balasubramanian, K.; Burghard, M. Chemically functionalized carbon nanotubes. Small 2005, 1, 180-192. [CrossRef]

67. Gottipati, M.K.; Samuelson, J.J.; Kalinina, I.; Bekyarova, E.; Haddon, R.C.; Parpura, V. Chemically functionalized single-walled carbon nanotube films modulate the morpho-functional and proliferative characteristics of astrocytes. Nano Lett. 2013, 13, 4387-4392. [CrossRef]

68. Chełmecka, E.; Pasterny, K.; Kupka, T.; Stobiński, L. DFT studies of COOH tip-functionalized zigzag and armchair single wall carbon nanotubes. J. Mol. Model. 2012, 18, 2241-2246. [CrossRef]

69. Kanakaraj, S.N.; Alvarez, N.T.; Gbordzoe, S.; Lucas, M.S.; Maruyama, B.; Noga, R.; Hsieh, Y.Y.; Shanov, V. Improved dry spinning process at elevated temperatures for making uniform and high strength CNT fibers. Mater. Res. Express 2018, 5, 065036. [CrossRef]

70. Dyke, C.A.; Tour, J.M. Covalent functionalization of single-walled carbon nanotubes for materials applications. J. Phys. Chem. A 2004, 108, 11151-11159. [CrossRef]

71. Gottipati, M.K.; Kalinina, I.; Bekyarova, E.; Haddon, R.C.; Parpura, V. Chemically functionalized water-soluble single-walled carbon nanotubes modulate morpho-functional characteristics of astrocytes. Nano Lett. 2012, 12, 4742-4747. [CrossRef] [PubMed]

72. Williams, M.G.; Gao, F.; BenDhiab, I.; Teplyakov, A. Carbon Nanotubes Covalently Attached to Functionalized Surfaces Directly through the Carbon Cage. Langmuir 2017, 33, 1121-1131. [CrossRef] [PubMed]

73. Adenier, A.; Chehimi, M.M.; Gallardo, I.; Pinson, J.; Vilà, N. Electrochemical oxidation of aliphatic amines and their attachment to carbon and metal surfaces. Langmuir 2004, 20, 8243-8253. [CrossRef] [PubMed]

74. Barbier, B.; Pinson, J.; Desarmot, G.; Sanchez, M. Electrochemical Bonding of Amines to Carbon Fiber Surfaces Toward Improved Carbon-Epoxy Composites. J. Electrochem. Soc. 1990, 137, 1757-1764. [CrossRef]

75. Lyskawa, J.; Bélanger, D. Direct modification of a gold electrode with aminophenyl groups by electrochemical reduction of in situ generated aminophenyl monodiazonium cations. Chem. Mater. 2006, 18, 4755-4763. [CrossRef]

76. Bélanger, D.; Pinson, J. Electrografting: A powerful method for surface modification. Chem. Soc. Rev. 2011, 40, 3995-4048. [CrossRef] [PubMed]

77. Amer, I.; Brandt, S. Synthesis and characterization of Poly(p-phenylenediamine) and its derivatives using aluminium triflate as a co-catalyst. Cogent Eng. 2018, 5, 1499701. [CrossRef]

78. Akalin, E.; Akyüz, S. Theoretical study of IR spectra of paraphenylenediamine. Vib. Spectrosc. 2000, 22, 3-10. [CrossRef] 
79. Guo, X.; Kulkarni, A.; Doepke, A.; Halsall, H.B.; Iyer, S.; Heineman, W.R. Carbohydrate-based label-free detection of escherichia coli ORN 178 using electrochemical impedance spectroscopy. Anal. Chem. 2012, 84, 241-246. [CrossRef]

80. Zhao, H.; Liu, J.; Song, X. Microstructural investigation of CNT-metal bonding behavior through computational simulations. J. Nano Res. 2015, 33, 118-125. [CrossRef]

81. Baranton, S.; Bélanger, D. Electrochemical derivatization of carbon surface by reduction of in situ generated diazonium cations. J. Phys. Chem. B 2005, 109, 24401-24410. [CrossRef] [PubMed]

82. Allongue, P.; Delamar, M.; Desbat, B.; Fagebaume, O.; Hitmi, R.; Pinson, J.; Savéant, J.M. Covalent modification of carbon surfaces by aryl radicals generated from the electrochemical reduction of diazonium salts. J. Am. Chem. Soc. 1997, 119, 201-207. [CrossRef] 